\title{
A Research Design to Build Effective Partnerships between City Planners, Developers, Government and Urban Neighbourhood Communities
}

\author{
Marcus Foth \\ Institute for Creative Industries and Innovation \\ Queensland University of Technology < m.foth@qut.edu.au $>$ \\ Barbara Adkinsor \\ Institute for Creative Industries and Innovation \\ Queensland University of Technology < b.adkins@qut.edu.au >
}

\begin{abstract}
Communities of place feature prominently in new urbanism movements and in master-planned inner-city developments that result from urban renewal. This paper's point of departure is the stark contrast between the widespread use of mobile and ubiquitous media and communications technology by urban dwellers on the one hand and endemic forms of urban alienation and the disappearance or non-existence of urban neighbourhood community identity on the other. Networked individualism introduces challenges to conventional understandings of 'place' and 'public places'. It opens up opportunities to build partnerships between architecture, city planning and urban studies in order to re-conceptualise the understanding of community and neighbourhood planning in the light of new media and network ICTs. However, such a reconceptualisation has not been achieved yet because of a lack of theoretical and practical understandings of the freedom and constraints and the social and cultural meanings that urban dwellers derive from their use of place-based ICT systems. The paper argues that in order to gain a better understanding of the continued purpose and relevance of urban neighbourhood communities in metropolitan areas and their changing role within a network society, the scope and structure of the communicative ecologies and social networks created and maintained by residents in urban residential real estate needs to be investigated empirically to inform city design and planning. The paper discusses a cross-disciplinary research design to build effective partnerships between city planners, developers, government, education and urban neighbourhood communities.
\end{abstract}

\section{Introduction}

This paper introduces a research design that seeks to build effective cross-disciplinary partnerships between academics and practitioners to enable the transfer of knowledge across a critical mass of people in the fields of media and communication studies, sociology, IT, community development, architecture, and urban policy, design and planning. It focuses on the intersection of new media opportunities and the challenges of urban renewal. The research seeks to build a cross-disciplinary understanding of how urban residents use new media and network ICT systems (e.g., internet and mobile phone applications) to facilitate access to and effective use of the social, cultural, educational and economic assets in their residential locale. The main site of study chosen for this project is the Kelvin Grove Urban Village in Brisbane which is the product of a new generation of heterogeneous urban master-planning with a high proportion of residential usage. It is the first inner-city development of its kind in Australia where public 
and private stakeholders have come together to plan and build an integrated community in an innovative way that comprises educational, residential, health, retail, recreational and business opportunities. The development project started in 2001 and the last development stage is scheduled for completion in 2008.

The vision informing the development of networked geographic communities in Australia and elsewhere has been articulated in terms of community-building: the capacity to engender a sense of community and belonging and sociability in estates and neighbourhoods. However, a large body of both theoretical and empirical work suggests that the networking and linking practices enabled by new media and ICTs are not likely to be focused on identifications based solely on co-location and place but on the meanings and usages residents derive from their interaction situated within place (Graham, 2004). 'Physical closeness does not mean social closeness.' (Wellman, 2001, p. 234).

In view of these findings, it is not surprising that a recent Australian study of an attempt to build a networked geographic community found that for some, the priority was not participation in the immediate community for its own sake. This apparent individualism, however, did not mean that resident's uses of ICT were not strategically oriented to other interests. Rather, resident's uses of ICTs were consistent with an orientation to broader participation in economic, educational, social and cultural life (Meredyth et al., 2004). This finding supports Woolcock's (1998) observation that it is possible to have too much social capital, particularly if it is built at the expense of - or out of context of - access to other linkages.

These issues of access, connection and usage, particularly in the context of education and culture are now being considered as part of education reform strategies (Adkins et al., 2003) and also taken up in the development of master-planned neighbourhoods and villages designed to facilitate integration with and access to educational and cultural precincts. The attempts to foster these connections through planning and development offer new opportunities to document whether and how factors such as co-location, the uses of new media and ICTs and local community building enable access to and participation in the fields of education and culture, democratic access to and effective use of local information and services, and the promotion of an innovation culture and economy locally.

Documenting these relationships, however, requires the development of a conceptual and methodological framework suited to bridging aspirations of new urban development with respect to integrated neighbourhood community planning, public space, urban design and building (De Villiers, 1997; Gleeson, 2004) with the yet unfulfilled potential of location-based new media and network ICT systems (Gaved \& Mulholland, 2004, 2005; Huysman \& Wulf, 2004; Rheingold, 2002). Such a conceptual and methodological framework will be presented here. This paper first reviews theoretical and empirical work in the sociology of networks, in order to identify emerging social formations that are facilitated through the use of ICT and New Urbanist planning strategies, and identifies questions arising from this concerning the processes likely to generate these social forms. We then propose a conceptual framework based on Sterne's (2003) application of Bourdieu's framework to technology use, a case study approach, and an ethnographic action research methodology as a means of focusing on these processes, with reference to the way these are suited to the study of new media and ICT use in a heterogeneous master-planned community site. We argue that this approach contributes to the development of a debate that goes beyond the pre-constructed meanings and practices associated with technology use in urban villages.

The aim of this paper is neither to report on final results nor on work-in-progress, but rather to present an innovative research design situated in the field of community informatics that is grounded in a crossdisciplinary theoretical and methodological framework. The intent of the design specifics is to build effective partnerships between academic disciplines as well as between private, public and community stakeholders such as city planners, developers, local government and urban neighbourhood communities.

\section{New Social Formations, New Media, New Urbanism}

The study's point of departure is the stark contrast between the widespread use of mobile and ubiquitous communications technology by urban dwellers on the one hand and endemic forms of urban alienation and the disappearance or non-existence of urban neighbourhood community identity on the other. In today's networked society, e-mail, instant messaging, online chats and other applications are instrumental in establishing and maintaining social ties, thus creating a private 'portfolio of sociability' 
(Castells, 2001, p. 132) which we refer to as an individual's 'communicative ecology' (Tacchi et al., 2003). Neighbours may still be part of a resident's social portfolio, but the communication devices used to maintain social ties are inherently place-independent and ephemeral. Getting to know someone in their role as a 'neighbour' is less likely than getting to know them in their role as a 'co-worker' or being the friend of a friend. Sociologists such as Wellman (2001; 2002; Wellman et al., 2003) describe how people construct their social networks with the help of new media tools. Wellman argues that while people become more accustomed with the features these tools offer, the nature of the social ties people establish and maintain changes from what used to be door-to-door and place-to-place relationships to what are now person-toperson and role-to-role relationships. Wellman terms the emerging qualities of this behaviour 'networked individualism'.

Previous studies that tried to make sense of contemporary new media usage rely on simple binary oppositions such as 'individual' vs. 'community', 'physical place' vs. 'cyberspace' or 'online' vs. 'offline' (DiMaggio et al., 2001; Giddens, 2003). This research departs from these compartmentalised dichotomies by creating a holistic theoretical framework that builds on the dual nature of 'the community' and 'the individual' inherent in networked individualism. For example, even as the internet grows exponentially, place-based units such as 'home', 'work' and 'school' remain at the core of our understanding of everyday life, and 'the economy itself increasingly takes form around real concentrations of people in real places' (Florida, 2003, p. 4). Human interaction thus takes place seamlessly in the virtual and physical 'space of flows' (Castells, 2004) that modern transportation and communication afford. Place and proximity continue to matter in every socio-economic aspect. This is evident by rising car and air travel sales (Wellman, 2001, p. 247), by people commuting to work instead of working from home, and by the formation of economic clusters, precincts and hot spots where industries based within the same value chain co-locate to take advantage of synergy effects. However, an empirically proven rationale has yet to be found that clarifies the conditions under which these synergy effects apply in the heterogeneous context of new residential urban developments.

Our research is also informed by Watters (2003) conceptualisation of 'urban tribes' - social clusters of under-35 year old urban dwellers. They represent a social network, a swarming group of friends who live in the same city and who are connected through a meshwork of strong and weak ties. The face-to-face interaction between members of urban tribes is supplemented by the use of new media and ICT applications. Watters' analysis of urban tribes provides further evidence for the shifting quality of community formations in urban settings towards social networks. He - as well as others (Fischer, 2001; Florida, 2003; Sobel, 2002) - critique Putnam's (2000) narrow interpretation of social capital.

Watters argues that 'social capital comes from much more fluid and informal (yet potentially quite close and intricate) connections between people. [S] ocial capital could as easily accrue among a tight group of friends yet still have an effect on the community at large.' (Watters, 2003, p. 116). Thus, our research builds on the fact that community assets include not only the formal skills of individuals and the tangible associations and institutions in a given locality (Kretzmann \& McKnight, 1993), but more and more the informal proximity-based social clusters and intangible networks of weak tie relationships that people build and maintain through new media and network ICTs. It is the intention of our work to contribute to a greater understanding of how these tacit and soft assets can be elicited, connected, networked and harnessed to become 'smart' assets in the service of both social and economic innovation in metropolitan areas.

\section{Challenges in New Media and New Urbanism}

In the context of urban renewal and new urbanism (De Villiers, 1997; Healy \& Birrell, 2004), networked individualism introduces challenges to conventional understandings of 'place' and 'public places'. It opens up opportunities for architecture, city planning and urban studies to re-conceptualise their understanding of community and neighbourhood planning in the light of new media and network ICTs (cf. Castells, 2004; Florida, 2003; Graham, 2004; Mitchell, 2003; Oldenburg, 2001; Walmsley, 2000). However, such a re-conceptualisation has not yet been achieved because of a lack of theoretical and practical understandings of the freedom and constraints and the social and cultural meanings that urban dwellers derive from their use of location-based ICTs. 
In particular, in master-planned communities, traditional conceptual models of community development limit action to tangible places of public interaction such as kindergartens, public schools, parks, libraries, etc. (Gleeson, 2004). This 'build it, they will come' approach lacks engagement with the findings of recent community development and community informatics research (Foth, 2004, 2006b; Gilchrist, 2004; Pinkett, 2003) that calls for an engagement with yet unanswered questions around the significance of social networks in urban neighbourhood community building. It also ignores both the human factors involved in urban renewal and socio-cultural animation (Foth, 2006a) of neighbourhoods as well as the potential that media and communication technology can offer urban residents (Day \& Schuler, 2004; Gaved \& Mulholland, 2004, 2005).

This resonates with developments in new media research (Jankowski, 2002; Matei \& Ball-Rokeach, 2003) which has moved on to analyse the new qualities of the 'third wave' of community media, that is, applications including web-based systems such as indymedia, community networks and other locationaware 'smart mob' technologies (Rheingold, 2002). In this light, Jankowski (2003) rightly argues that there is an unfulfilled promise to establish theoretically grounded models and a need to depart from simple dichotomies. The holistic approach proposed here will respond to this call.

Building on this significance, the research design will innovate and produce new knowledge in three areas which are now discussed in turn.

\section{The Use of Network Theory in the Context of Community Networks}

Dunbar (1996) suggests that the size of human social networks is limited for biological and sociological reasons to a value of around 150 people. Barabási (2003) provides a more far-reaching overview of recent advances in network theory and their impact on business, science and everyday life. Some ideas are crucial in understanding social networks: They decrease or increase in size, that is, they are dynamic and not static. Their structure is not random or chaotic, but follow preferential attachment ('rich get richer') and fitness ('fit get richer').

In the context of community networks, Jankowski et al. (2001, p. 113) support this thesis with empirical research by pointing out that 'those geographic communities already rich in social capital may become richer thanks to community networks, and those communities poor in social capital may remain poor'. Hampton \& Wellman (2003, p. 283) support this notion by stating that, 'connectivity seems to go to the connected: greater social benefit from the Internet accrues to those already well situated socially'. Yet unanswered questions are, what constitutes 'richness' and 'fitness' in urban social settings, how do residents get 'rich' and become a 'hub' in their social network, and how can social networking systems facilitate 'enrichment' and inclusion?

\section{Ethnographic Action Research in Urban Contexts}

The current authors and their colleagues have developed, applied, tested and refined a research methodology specifically to generate new understandings of ICTs and their social applications (Foth \& Tacchi, 2004; Tacchi et al., 2003). This method combines ethnography with action research. Our research design employs ethnography for its ability to place people within a wider and holistic context - in this case the interactions of urban residents with new technology and their wider communicative ecologies.

Action research is used to bring about new activities and interventions based on new perceptions of situations achieved through ethnography. We use ethnography to guide the research process and action research to link the findings back into the project's ongoing development. This research project will form part of a larger collaborative research agenda that is building a growing body of knowledge to redefine innovative research strategies on, and achieve better understandings of, emerging technologies and their implications and uses in social and place-based contexts.

The development of Ethnographic Action Research was initiated by the UK Government's Department for International Development (DfID) and UNESCO as a transferable methodology to evaluate and develop new media and network ICT initiatives. The core methodology is now being applied and tested in different contexts, such as the use of ICT for poverty reduction (Tacchi, 2004), and the use of new media and 
network ICTs in a project to establish a 'Youth Internet Radio Network' (Hartley et al., 2003). This research project will develop a customised version of the Ethnographic Action Research methodology that takes the specific characteristics of new media and ICT use in urban settings into account.

\section{A Theoretically Grounded Model of Community Innovation}

This study's capacity to articulate current understandings of the contexts and practices of information and technology use facilitated by new master-planned urban villages will inform innovation in the field of new media and ICT. The development of this field is characterised by the rapid proliferation of new scientific and technological knowledge. Smits (2002) notes that this new knowledge often fails to lead to successful products, services and solutions to social problems. This issue has in part been identified as associated with the need for a focus on innovation rather than simply invention, that is, for a focus on not only the development of new knowledge and technology but also, among other things, on the design of products that pay sufficient attention to the intensifying interface between user and producer (Smits, 2002).

This research design addresses these critical challenges in relation to the use of new media and network ICTs by delivering a broader understanding of the new types of social formations in urban settings. These are conceptualised as facilitators of resident's access to education, culture and economic life with a view to informing the unknown potential for socio-economic and cultural-economic innovation to occur in local community contexts through 'effective use' of new media and ICT applications (Gurstein, 2003, 2004).

\section{Research Design and Methodology}

We propose an approach that treats a physical location such as a village as a site of embedded cases of different groups' use of new media and ICT to facilitate economic, educational and cultural participation. The paper then outlines a specific approach to theory building - ethnographic action research - which is specifically suited to building theory based on an intensive understanding of the communicative ecologies involved in new media and ICT use in this context.

\section{Conceptual Framework and Rationale}

The emerging area of research outlined above requires a conceptual and methodological framework that is capable of informing the development of new configurations and systems of ICTs that are suited to the needs and interests of different groups and that enable broader educational, cultural and economic participation. The framework adopted thus needs to be able to focus on the complex mix of social, spatial, technical, cultural and temporal relationships in which uses of ICTs are embedded, but also needs to enable the study of everyday practices and experiences of these relationships. Sterne (2003) has recently pointed to the suitability of Bourdieu's (1986) concepts of habitus, field and capital for capturing the relationships in which technology use is embedded, arguing that it is a perspective capable of overcoming the binary oppositions between technology and society that have plagued technology studies.

Bourdieu's framework proposes that experience must be understood analytically in terms of one's position in social space - an abstract system of social relations - but also in terms of applications of habitus. As a set of dispositions, habitus comprises inculcated schemes of action in the form of embodied, pre-reflective dispositions that are applied in practice. Applications of habitus occur in the context of fields or social domains of activity.

For Bourdieu, the concept of field was introduced as a key dimension of his three dimensional model, providing a focus on the way one's position in social space and habitus were applied in a specific domain. In the context of field, the acquisition of various kinds of capital had an important influence on the extent to which social actors could compete for, gain and maintain positions, providing for a study of the way a specific habitus could be applied in the context of particular positions. This enables a focus on prises de positions, 'position-takings' or stances. In this framework, a specific stance must be understood as the product of the 'meeting of two histories' of positions and dispositions. 
This focus on both positions and dispositions in the context of the capitals (social, cultural, economic, symbolic and educational) at stake provide for a systematic identification of the use of ICT in the village in terms of both networks of relationships and individuals' experience of them. For the purposes of this study, cultural and educational capital may take a physical and institutional form: proximity to the institutions and facilities of theatres, universities, information and communication technologies. These relationships may be supported symbolically in urban design and representation of neighbourhoods, villages, and housing as specific kinds of 'communities'. However, these capitals are also possessed at different levels in the habitus of individuals, providing for different levels and kinds of improvised responses. The study of the use of ICT in the village thus becomes a question of the extent to which individuals and groups are able to appropriate these capitals in their physical form, and the broader participation this appropriation enables.

The research design employed by the study is sensitive to the different levels of analysis designated by this framework. This is manifested in strategies for data selection, collection and analysis. Further however, it is also a framework suited to building theory iteratively in a way which attends to the intensifying interface between user and producer that characterises innovation oriented research.

\section{Research Site and Principles of Case Selection}

A case study is a single bounded entity, studied in detail, with a variety of methods, over an extended period, and is selected because it is theoretically representative of the relationships to be investigated (Yin, 2003). Kelvin Grove Urban Village is a result of the redevelopment of a Brisbane inner-city Defence Force site into a village incorporating tertiary education, residential, leisure and business activities. In part, it is a planning strategy that reflects urban planning challenges arising from rapid population growth and the associated escalation in housing demand in Brisbane. It was proposed that new residential strategies would be required to meet future population growth, involving a shift from large-scale master-planned subdivisions to infill development and smaller-scale subdivisions. This was also to involve higher density developments (Healy \& Birrell, 2004). The higher density inner-city development was thus consistent with these planning strategies.

However, its location and design also reflects a desire to achieve a higher level of integration between residential, commercial, educational, cultural and employment activities (Healy \& Birrell, 2004). The master plan describes it as "a diverse city fringe neighbourhood linking learning with enterprise, creative industry with community [...] creating a new part of Brisbane that offers a unique living solution" (Department of Housing \& Queensland University of Technology, 2004). Thus the planned social heterogeneity of the development represents a further key feature of the new urbanist aspirations of the development with a planning focus on diversity in housing types, land uses and social groups (De Villiers, 1997). This aspect of the development is of specific theoretical interest to the study reflecting a planning strategy that strategically co-locates groups such as older people, younger people, social housing clients with those with greater advantages in the field of housing, in an inner-city complex close to the physical and institutional forms of cultural capital both within the community and in the city centre.

Further, in keeping with the new urbanist ideal, new media and ICTs are proposed to play a key role in aspects of this integration providing opportunities for people to "work where they choose to live, connecting them with the world, and encouraging intellectual growth." (KGUV development newsletter). As well as a focus on facilitating access to other fields, the village is also considering the development of a community intranet to enhance participation in the civic life of the local village and the broader metropolitan area. Thus the site provides an opportunity to investigate the relationships involved in the uses of ICTs with respect to the way this enables participation in the fields of culture, education, economic and civic life. As such it is theoretically representative of a development that deliberately encapsulates the relationships that are the focus of this study.

Within the broader case, the commitment to diversity provides for the study of the way different groups use new media and ICTs. To accommodate this focus, the study will adopt an embedded case study design, which, according to Yin (2003), is advantageous when logical subunits within the case can be defined. The subunits to be studied will be selected to allow for the examination of different logics, rationales, purposes and uses of ICTs employed by different individuals and groups in participating in various fields. 


\section{Research Progression, Timeline and Data Collection}

The case study site allows us to investigate a master-planned community site during development and completion. The timing affords a unique opportunity to research the development stages of the site and to examine how 'master-planning' can or cannot create 'community' (Gleeson, 2004). The methodology comprises three components:

- baseline survey;

- ethnographic immersion;

- action research interventions, including socio-cultural animation (Foth, 2006a; Hearn \& Foth, 2005).

This mixed quantitative/qualitative data obtained will be analysed, and using maximum variation sampling (Patton, 1990) a smaller sub-set of individuals will be selected who will be in-depth participants of the study. The sampling will take into consideration socio-demographic (age, gender, income, occupation, relationship status, housing type) as well as personal communication circumstances (number of social nodes, roles, location and frequency of interaction). This will allow for a comparative analysis of length of residency, size of building complex as well as social, cultural, spatio-temporal and technical relationships relevant to new media and network ICT use. This analysis will take the form of a matrix of questions and indicators, developed over the course of the research, that indicate the kinds of processes, issues and structures that are in place and that are being constructed in the communicative ecologies inhabited by residents of the case study site.

Ethnographic immersion follows the initial baseline research. The methods to be used here form part of a methodological toolkit employed in Ethnographic Action Research and include textual analysis, participant observation, semi-structured interviews, and focus groups. Data collected through these methods will be fed into meta-level mapping activities that target broader issues of access, uses, meanings and relationships.

Ethnographic immersion prepares for action research interventions to occur. While all case study designs build and/or enhance theory, this study will employ a specific theory building strategy towards socio-economic innovation. As mentioned above, the overarching methodological approach chosen for the research is based on combining two research approaches - ethnography and action research (Foth \& Tacchi, 2004; Tacchi et al., 2003). Ethnography places social networks in relevant local and non-local contexts. Action research follows an iterative cycle of inquiry, critical reflection and action which means that the research process is tightly connected to the activities of residents in three possible ways (Hearn \& Foth, 2005):

1. Active participation - the residents who should benefit from the research participate in critically defining and reflecting upon the aims and direction of the project and in interpreting and drawing conclusions from it;

2. Action-based methods - the activities and experiences of participants generate knowledge alongside, or in combination with, more formal methods, both qualitative and quantitative; and,

3. Generating action - research is directly aimed at generating medium and long-term plans, including entrepreneurial plans; ideas for new initiatives; solving problems; targeting sectors of the user constituency; finding new resources or partners. This depends on the interaction with participants.

One of the strong benefits of combining action research with ethnography is the opportunity it affords to sustain an ongoing process to drive and sustain urban neighbourhood community development in the case study site beyond the lifetime of the research project itself. We are committed to document this process and evaluate means for transferability to and appropriation at other sites.

\section{Conclusion and Outlook}


The research design discussed in this paper is a pathway towards a theoretical and empirical investigation into the interaction between social and cultural capital and the ways they function to facilitate access to the socio-cultural and socio-economic life of cities. The specific objectives of the research design are to:

- Re-conceptualise and innovate in understandings of communicative ecologies and social networks created and maintained by residents and tenants of inner-city master-planned community developments in Australia;

- Build a cross-disciplinary academic framework that connects new media, community development, socio-economic innovation and urban studies paradigms;

- Employ an innovative research methodology to map the relationship between the evolving personal communication patterns of urban residents, their locality and public space;

- Understand the challenges urban residents face when using interactive new media and ICT systems and devices to facilitate and support social communication and socio-economic innovation;

- Critically analyse the social, cultural and symbolic meaning that urban residents derive from the applications, devices and methods they employ to create and maintain social and economic networks in the context of place.

A recent Australian Federal Government discussion paper suggests that "there is vast potential to use ICT to build social capital and contribute to community development and formation. However, [...] it is largely untapped and unrecognised in many areas. For ICT use to move beyond bonding - to harness its power for bridging and linking to resources that enhance economic and social development - it needs more attention to the type of social capital being developed." (DCITA, 2005).

Research that situates itself in the nexus between people, place and technology and that contributes to a broader understanding of the dimensions of social capital in the context of ICT and place will benefit society in a number of ways (Davies, 2003, 2004; Foth, 2003). It will contribute to a greater understanding of the factors and conditions that stimulate an innovation culture in local communities (Florida, 2003; Gurstein, 2004). The development of methods and systems to foster effective information use (Gurstein, 2003) in and across inner-city neighbourhoods and residential apartment buildings will assist local and state government efforts to encourage public consultation, civic engagement and open debate. It will also support access to local information and services by employing a mixed public/ private approach. As well, understanding the issues and challenges including opportunities and strengths in forming a local meshwork of social networks will help urban dwellers negotiate the complex web of daily choices, access a greater social safety net, and participate in the socio-cultural and socio-economic life in their city. This in turn will lead to greater social inclusion, urban sustainability and healthier local economies.

\section{Acknowledgements}

An earlier version of this paper appears in G. Erwin, W. Taylor, A. Bytheway \& C. Strümpfer (Eds.) (2005). Proceedings: Community Informatics Research Network (CIRN) conference (pp. 341-354). Cape Town, South Africa: Cape Peninsula University of Technology. This research is supported under the Australian Research Council's Discovery funding scheme (DP0663854). Dr Marcus Foth is the recipient of an Australian Postdoctoral Fellowship. Further support has been received from the Queensland Department of Housing, the Urban Development Institute of Australia (Queensland) and the Unit Owners Association of Queensland. The authors would like to thank Greg Hearn, Michael Keane, Richard Jones, Bob Breakspere, John Western, Jean Burgess, Jo Tacchi, Steffen Lehmann, Michael Gurstein and anonymous reviewers for helpful comments and feedback on earlier versions of this paper.

\section{References}


Adkins, B., Grant, E., Summerville, J., Barnett, K., \& Buys, L. (2003). Community and learning for the new economy. Paper presented at the Social Change in the 21st Century Conference, Centre for Social Change Research, QUT, Brisbane.

Barabási, A.-L. (2003). Linked: How everything is connected to everything else and what it means for business, science, and everyday life. New York: Plume.

Bourdieu, P. (1986). The forms of capital. In J. G. Richardson (Ed.), Handbook of theory and research for the sociology of education (pp. 241-258). New York, NY: Greenwood Press.

Castells, M. (2001). Virtual communities or network society? In The Internet galaxy: Reflections on the Internet, business, and society (pp. 116-136). Oxford: Oxford University Press.

Castells, M. (2004). Space of flows, space of places: Materials for a theory of urbanism in the information age. In S. Graham (Ed.), The Cybercities reader (pp. 82-93). London: Routledge.

Davies, W. (2003). You don't know me, but. Social capital \& social software. London: The Work Foundation.

Davies, W. (2004). Proxicommunication: ICT and the local public realm. London: The Work Foundation.

Day, P., \& Schuler, D. (Eds.). (2004). Community practice in the network society: Local action / global interaction. London: Routledge.

DCITA. (2005, Feb 18). Community ICT transformation discussion papers and case studies. Retrieved Feb 28,2005 , from

http://www.dcita.gov.au/ie/community_connectivity/community_ict_transformation_discussion_p apers_and_case_studies

De Villiers, P. (1997). New urbanism: A critical review. Australian Planner, 34, 30-34.

Department of Housing, \& Queensland University of Technology. (2004). Kelvin Grove Urban Village master plan. Retrieved Jul 3, 2005, from http://www.kgurbanvillage.com.au/about/resources.shtm

DiMaggio, P., Hargittai, E., Neuman, W. R., \& Robinson, J. P. (2001). Social implications of the Internet. Annual Review of Sociology, 27, 307-336.

Dunbar, R. I. M. (1996). Grooming, gossip, and the evolution of language. Cambridge, MA: Harvard University Press.

Fischer, C. (2001, Aug). Bowling alone: What's the score? Paper presented at the "Author Meets Critic: Putnam, Bowling Alone" session of the meetings of the American Sociological Association, Anaheim, CA.

Florida, R. L. (2003). Cities and the creative class. City and Community, 2(1), 3-19.

Foth, M. (2003). Connectivity does not ensure community: On social capital, networks and communities of place. In S. Marshall \& W. Taylor (Eds.), Proceedings of the 5th International Information Technology in Regional Areas (ITiRA) conference 2003 (pp. 31-39). Rockhampton, QLD: Central Queensland University Press.

Foth, M. (2004). Designing networks for sustainable neighbourhoods: A case study of a student apartment complex. In G. Johanson \& L. Stillman (Eds.), Community Informatics Research Network (CIRN) 2004 colloquium and conference proceedings. 29 Sep - 1 Oct 2004 (Vol. 1, pp. 161-172). Prato, Italy.

Foth, M. (2006a). Sociocultural animation. In S. Marshall, W. Taylor \& X. Yu (Eds.), Encyclopedia of developing regional communities with information and communication technology (pp. 640-645). Hershey, PA: Idea Group Reference.

Foth, M. (2006b). Analyzing the factors influencing the successful design and uptake of interactive systems to support social networks in urban neighborhoods. International Journal of Technology and Human Interaction, 2(2), 65-79. 
Foth, M., \& Tacchi, J. (2004). Ethnographic action research website. In I. Pringle \& S. Subramanian (Eds.), Profiles and experiences in ICT innovation for poverty reduction (pp. 27-32). New Delhi, India: UNESCO.

Gaved, M. B., \& Mulholland, P. (2004, Sep 19-22). Grassroots initiated networked communities: a viable method of overcoming multiple digital inequalities within communities of locality? Paper presented at the Association of Internet Researchers conference (AoIR 5.0), Sussex, UK.

Gaved, M. B., \& Mulholland, P. (2005, Jan 3-6). Grassroots initiated networked communities: A study of hybrid physical / virtual communities. Paper presented at the 38th Hawaii International Conference on System Sciences (HICSS), Big Island, Hawaii.

Giddens, A. (2003). Runaway world: How globalisation is reshaping our lives (2nd ed.). New York: Routledge.

Gilchrist, A. (2004). The well-connected community: A networking approach to community development: The Policy Press.

Gleeson, B. (2004). Deprogramming planning: Collaboration and inclusion in new urban development. Urban Policy and Research, 22(3), 315-322.

Graham, S. (Ed.). (2004). The cybercities reader. London: Routledge.

Gurstein, M. (2003). Effective use: A community informatics strategy beyond the digital divide. First Monday, 8(12).

Gurstein, M. (2004, Mar 31 - Apr 2). Community innovation and community informatics: Building national innovation capability from the bottom up. Paper presented at the Community Network Analysis (CNA) conference, Brighton, UK.

Hampton, K. N., \& Wellman, B. (2003). Neighboring in netville: How the Internet supports community and social capital in a wired suburb. City and Community, 2(4).

Hartley, J., Hearn, G., Tacchi, J., \& Foth, M. (2003). The Youth Internet Radio Network: A research project to connect youth across Queensland through music, creativity and ICT. In S. Marshall \& W. Taylor (Eds.), Proceedings of the 5th International Information Technology in Regional Areas (ITiRA) conference 2003 (pp. 335-342). Rockhampton, QLD: Central Queensland University Press.

Healy, E., \& Birrell, B. (2004). Housing and community in the compact city (Positioning Paper). Melbourne, VIC: Australian Housing and Urban Research Institute.

Hearn, G., \& Foth, M. (2005). Action research in the design of new media and ICT systems. In K. Kwansah-Aidoo (Ed.), Topical issues in communications and media research (pp. 79-94). New York, NY: Nova Science.

Huysman, M., \& Wulf, V. (Eds.). (2004). Social capital and information technology. Cambridge, MA: MIT Press.

Jankowski, N. W. (2002). Creating community with media: History, theories and scientific investigations. In L. A. Lievrouw \& S. M. Livingstone (Eds.), Handbook of new media: Social shaping and consequences of ICTs (pp. 34-49). London: Sage.

Jankowski, N. W. (2003). Community media research: A quest for theoretically-grounded models. Javnost - The Public, 10(1), 5-14.

Jankowski, N. W., Van Selm, M., \& Hollander, E. (2001). On crafting a study of digital community networks: Theoretical and methodological considerations. In L. Keeble \& B. D. Loader (Eds.), Community informatics: Shaping computer-mediated social relations (pp. 101-117). New York: Routledge.

Kretzmann, J. P., \& McKnight, J. L. (1993). Building communities from the inside out: A path toward finding and mobilizing a community's assets. Chicago, IL: Institute for Policy Research. 
Matei, S. A., \& Ball-Rokeach, S. J. (2003). The Internet in the communication infrastructure of urban residential communities: Macro- or mesolinkage? Journal of Communication, 53(4), 642-657.

Meredyth, D., Ewing, S., \& Thomas, J. (2004). Neighbourhood renewal and government by community. International Journal of Cultural Policy, 10(1), 85-101.

Mitchell, W. J. (2003). Me++: The cyborg self and the networked city. Cambridge, MA: MIT Press.

Oldenburg, R. (2001). Celebrating the third place. New York: Marlowe \& Co.

Patton, M. Q. (1990). Qualitative evaluation and research methods (2nd ed.). Newbury Park, CA: Sage.

Pinkett, R. D. (2003). Community technology and community building: Early results from the creating community connections project. The Information Society, 19(5), 365-379.

Putnam, R. D. (2000). Bowling alone: The collapse and revival of American community. New York: Simon $\&$ Schuster.

Rheingold, H. (2002). Smart mobs: The next social revolution. Cambridge, MA: Perseus.

Smits, R. (2002). Innovation studies in the 21st century: Questions from a user's perspective. Technological Forecasting \& Social Change, 69, 861-883.

Sobel, J. (2002). Can we trust social capital? Journal of Economic Literature, XL, 139-154.

Sterne, J. (2003). Bourdieu, technique and technology. Cultural Studies, 17(3/4), 367-389.

Tacchi, J. (2004). Researching creative applications of new information and communication technologies. International Journal of Cultural Studies, 7(1), 91-103.

Tacchi, J., Slater, D., \& Hearn, G. (2003). Ethnographic action research handbook. New Delhi, India: UNESCO.

Walmsley, D. J. (2000). Community, place and cyberspace. Australian Geographer, 31(1), 5-19.

Watters, E. (2003). Urban tribes: Are friends the new family? London: Bloomsbury.

Wellman, B. (2001). Physical place and cyberplace: The rise of personalized networking. International Journal of Urban and Regional Research, 25(2), 227-252.

Wellman, B. (2002). Little boxes, glocalization, and networked individualism. In M. Tanabe, P. van den Besselaar \& T. Ishida (Eds.), Digital cities II: Second Kyoto workshop on digital cities (LNCS 2362, pp. 10-25). Heidelberg, Germany: Springer.

Wellman, B., Quan-Haase, A., Boase, J., Chen, W., Hampton, K. N., Díaz de Isla Gómez, I., et al. (2003). The social affordances of the Internet for networked individualism. Journal of Computer-Mediated Communication, 8(3).

Woolcock, M. (1998). Social capital and economic development: Towards a theoretical synthesis and policy framework. Theory and Society, 27(2), 151-208.

Yin, R. K. (2003). Case study research: Design and methods (3rd ed.). Thousand Oaks, CA: Sage. 